\title{
Digital Gifts and Tourism Mementos: A Sustainable Approach
}

\author{
Panagiotis Mantas ${ }^{1}$, Zafeiria-Marina Ioannou ${ }^{2}$, Emmanouil Viennas ${ }^{2}$, George Pavlidis ${ }^{2}$ \\ and Evangelos Sakkopoulos $3, *$ (D) \\ 1 School of Science and Technology, Hellenic Open University, 26335 Patras, Greece; std130985@ac.eap.gr \\ 2 Department of Computer Engineering and Informatics, University of Patras, 26504 Patras, Greece; \\ ioannouz@ceid.upatras.gr (Z.-M.I.); biennas@ceid.upatras.gr (E.V.); pvlds@ceid.upatras.gr (G.P.) \\ 3 Department of Informatics, University of Piraeus, 26504 Patras, Greece \\ * Correspondence: sakkopul@unipi.gr
}

Citation: Mantas, P.; Ioannou, Z.-M.; Viennas, E.; Pavlidis, G.; Sakkopoulos, E. Digital Gifts and Tourism Mementos: A Sustainable Approach. Sustainability 2022, 14, 98. https:/ / doi.org/10.3390/su14010098

Academic Editor: Mark A. Bonn

Received: 22 November 2021 Accepted: 15 December 2021 Published: 22 December 2021

Publisher's Note: MDPI stays neutral with regard to jurisdictional claims in published maps and institutional affiliations.

Copyright: (c) 2021 by the authors. Licensee MDPI, Basel, Switzerland. This article is an open access article distributed under the terms and conditions of the Creative Commons Attribution (CC BY) license (https:// creativecommons.org/licenses/by/ $4.0 /)$.

\begin{abstract}
Touristic destinations all around the world are struggling to digitally transform the touristic experience and the touristic products they offer and to capitalize a good experience with new tourists and returning ones. There is a lot of research on digital solutions assisting tourism, but it does not provide a follow-up digital product, therefore depending only on physical gifts, postcards and mementos. In this work, we propose a novel platform that can provide a personalized digital memento or digital gift for every route or tourist destination that can become the digital point of reference of visitors' experience giving new dimensions for commercialization to the existing physical mementos at the gift shops. The purpose of this study is to analyze what comprises a memorable touristic experience and to design and, finally, present a total solution that builds and offers a personal e-souvenir of a touristic experience to the tourist for him to hold, sport and share just using his mobile phone. We propose a digital memento-building platform that includes the personalized experience in visits taking place while in vacations. The visitors are usually taking pictures along routes they follow that later need further organization and processing and that in no way substitutes the physical mementos. In our approach, we propose a solution that generates a unique and personalized esouvenir through a collage of the selfies and photos creating the digital equivalent of the touristic postcards but in our case personalized with the visitor photos with minimum amount of effort and produced real-time. Our approach is also providing a platform to the photographers and designers of touristic destinations to build and graphically generated memento artifacts-templates specific for one or more destinations or routes. In this way, the approach serves the tourism industry vertically, covering all aspects, i.e., the tourist-visitor, the tourism professional players such as photographers, designers of physical mementos and, of course, the touristic destination providing a digital footprint to server marketing of the destination through sharing on social media and word-of-mouth, of course. To support our approach, we have built and run a fully working prototype in the touristic center of Athens, Greece, with real users and designers for several weeks during summer vacations. The results have been greatly encouraging from end-users and professionals. The study shows that it is possible for various lines of business to come together and work along one another for an improve touristic experience using mobile technologies in a personalized, targeted approach. The touristic destination, graphic designers, photographers, tourist agent specialists, software developers and visitors can all now have a digital personalized memorable gift from the visit.
\end{abstract}

Keywords: personalized souvenir; personalized digital gift; digital memento; digital personalized postcards

\section{Introduction}

Tourism in many countries is one of the key elements of their economy and contributes a large percentage to these countries' respective GDPs. It is no coincidence that in such countries the use of touristic goods such as climate conditions, gastronomic habits, points of interest and attractions should be exploited for economic development and identifying 
these goods can be a possible way out of an economic crisis. It is also no coincidence that tourism directly and indirectly provided 25\% of Greece's GDP in 2018 [1] amid an economic recession, while in 2019, tourism showed a record rise for the country. In 2020, tourism contributed to the recession from the effects of the pandemic caused by the COVID-19 virus due to its large contribution to the country's GDP during the previous years [2]. Other countries and regions have seen changes in the behaviour of touristic experiences due to the pandemic, too [3].

Tourism, as a tertiary productive sector of a country's economy, has been inextricably linked to information technology in recent years. Both direct and indirect tourism use information technology in ticketing systems, hotel and restaurant reservation systems, museum and archaeological site presentations, online and offline tour guides, etc.

On top of the penetration of information technology in every productive sector, as well as in tourism back-end systems, there is a great evolution in computers and personal electronic devices such as tablets or smartphones.

There are a lot of applications developed towards tourism assistance, offering a broad set of features, but they do not propose any approach for encouraging building a personalized digital memento or digital gift that will become the point of reference of their experience such as a physical memento does. From guided tours to tour planning applications, we can see the absence of significance ascribed in the value of a digital memento. Table 1 shows a comparison of the following features across various tour guidance applications: F01: GPS assisted, Self-guided walking tours; F02: Travel articles; F03: Offline maps; F04: "FindMe" feature; F05: "Trackme" feature; F06: Turn-by-turn travel directions; F07: Create own walking tour; F08: Audible information; F09: Review, rate and share tours and places; F10: Price and cost comparison; and F11: Online collaboration.

Table 1. Touring Applications feature comparison.

\begin{tabular}{ccccccc}
\hline & GPSmyCity & Geotourist & Trips by LP & Trip Advisor & Wanderlog & Route4Me \\
\hline F01 & $\checkmark$ & $\checkmark$ & & & $\checkmark$ & $\checkmark$ \\
F02 & $\checkmark$ & & $\checkmark$ & $\checkmark$ & & \\
F03 & $\checkmark$ & & & $\checkmark$ & $\checkmark$ & $\checkmark$ \\
F04 & $\checkmark$ & & & & & \\
F05 & $\checkmark$ & & & & & $\checkmark$ \\
F06 & $\checkmark$ & & & & $\checkmark$ & \\
F07 & $\checkmark$ & $\checkmark$ & & $\checkmark$ & $\checkmark$ & \\
F08 & $\checkmark$ & $\checkmark$ & & $\checkmark$ & & \\
F09 & & $\checkmark$ & $\checkmark$ & & $\checkmark$ & \\
F10 & & & & & & \\
F11 & & & & & & \\
\hline
\end{tabular}

Other platforms and services such as Google's $\mathrm{s}^{\mathrm{TM}}$ and Apple's $\mathrm{s}^{\mathrm{TM}}$ products might offer products more related to the creation of e-souvenir features, such as videos, photos and even image correction services, but none of them offers these features under the same "roof" with a full fledged touring app.

If we were traveling to a location 150 years ago, the only thing we could take with us, apart from our evaporating memories, was to write about the travel experience on paper. Later, with the invention of photography, we would go to a professional photographer to take a photo of us in his studio, having behind us a monument poster. With the invention of portable cameras, we would buy whole measures of film and take pictures with caution, however, because there was a limit to the number of shots.

However, today, with the ability to download literally thousands of digital souvenirs [4], which after the trip can end up on a hard drive and never be opened, if not worse, the storage medium is damaged, at best some photos will be able to reach social media. Even better, they can "collect some likes". 
The purpose of this study is to analyze what comprises a memorable touristic experience, design and finally develop a mobile solution that builds and offers a personal e-souvenir of this touristic experience to the tourist for him to hold, sport and share.

The paper is organized as follows: Section 2 discusses more details on the current state of play and the problem environment. Section 3 discusses previous work and related issues. Section 4 shortly discusses the general architecture of the fully working prototype that is functioning on all mobile and desktop platforms based on a progressive app approach. Section 5 analytically discusses the proposed user flows to show that the personalisation of memorable experiences can be achieved in few steps and that it can be embedded in existing e-guide apps following our proposed approach. Section 6 presents the experimental and real user evaluation. Section 7 concludes the paper with the discussion and presentation of future steps.

\section{Methodology}

We propose a digital memento that will serve as a dynamic postcard of the personalized experience in the routes and visits taking place while in vacations. The visitors are usually taking picture along routes they may follow that later need further organization and processing. In our approach, we minimize the time needed for post processing and we propose a solution that generates a unique and personalized e-souvenir through a collage of the selfies and photos, creating the digital equivalent of touristic postcards but, in our case, personalized with the visitor's photos. Taking all the above in regard, a solution was designed and implemented contributing the following to the industry:

- $\quad$ Guided process to assist users in taking a photograph (e.g., selfie) while on a trip;

- Automatic creation of an e-souvenir [4], a collage of landscape and selfie photos, provided as a digital cart-postal;

- An open platform that gives the photographers and graphic designers the means to express themselves and create cart-postal images that will later be personalized for a user;

- An ecosystem for digital organization of memories that accompanies self-guided tour apps.

When the user selects to create the e-souvenir, the stored images are returned to the user as a single digital memento for sharing or storing, giving a memorable uniquely personalized digital postcard following the general process outlined in Figure 1.

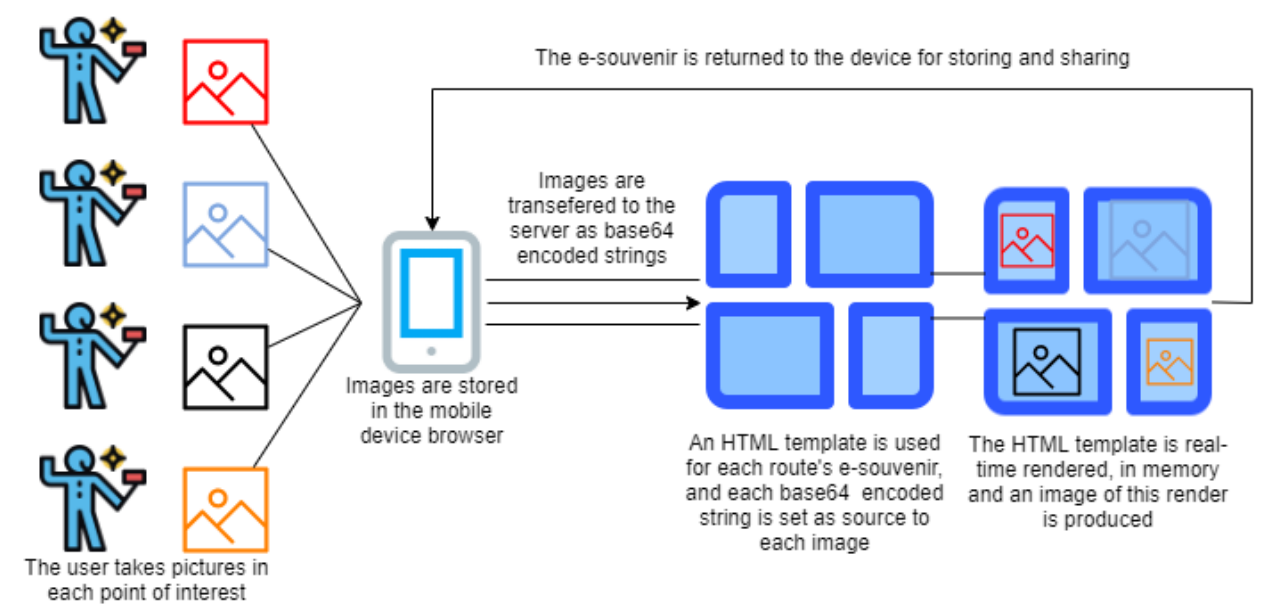

Figure 1. Transformation flow and e-souvenir creation.

Our approach takes into consideration the photographers' and designers' lines of business in order to provide them with a platform to build graphically generated templates specific to one or more routes. In this way, the approach serves the tourism industry vertically, covering all aspects, i.e., the tourist-visitor, the tourism professional players such 
as photographers, designers of physical mementos and, of course, the touristic destination providing a digital footprint to the server marketing of the destination through sharing on social media and word-of-mouth, of course.

For the best touristic experience, various lines of business should come together and collaborate to achieve the best result. This experience reaches far more than one person, or one company. Many different skills have to be put together, so that the tourist receives a memorable experience. In Figure 2, the various skills needed are shown.

In particular, four major categories of professionals could work together together with the touristic destination and, of course, with the end-user visitor, in a unified platform for the final result:

- A tourist guide should choose the P.o.I.s (Points of Interest) that the suggested route consists of. Their exact location coordinates and a short description of the point, with some information about the mentioned point, should be provided.

- Photographers must visit these points of interest. Pictures are taken both for the landscape of the point as well as pictures of the future visitor (e.g., selfie photo) using a model. The landscape photos will act as the default placeholder for the final souvenir, and the model photos will be the example shown to the tourist about how to take the picture. Text notes about how to take the picture (where and how to stand, camera orientation, etc.) can be provided here.

- Graphic design specialists create the form of the finally generated souvenir. Taking in regard the number of points consisting the route and their respective photos, the souvenir template is laid out. In addition, the graphic designer is responsible for the creation of watermark-overlaid images that might be used as a helpful tool for the tourist.

- Finally, front-end developers might or might not be needed. If special characteristics are needed for the final souvenir (e.g., the dynamic display of local time and date), some programming skills might be useful.

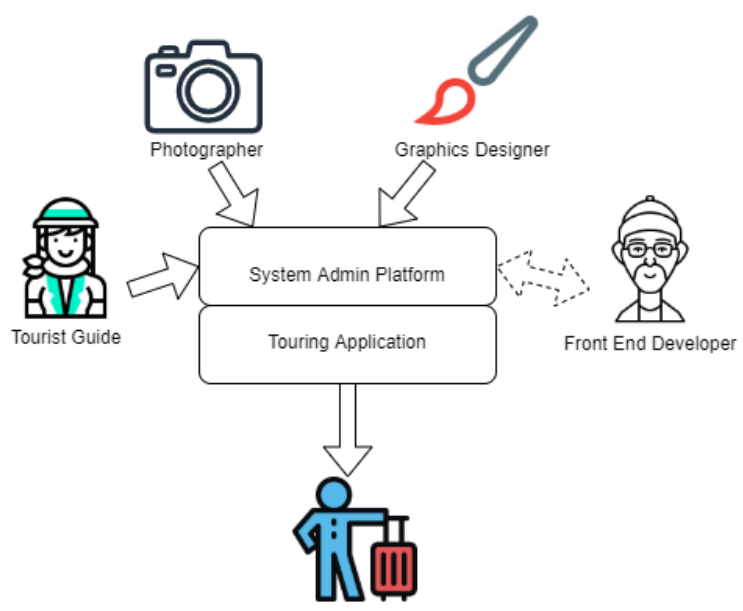

Figure 2. Business collaboration. How various lines of business interact for the final touristic experience.

With the contribution of these combined skills, a new form of a personalized e-souvenir is achievable. This time, for those not very keen to photographic techniques, the taking of the photographs are guided. In addition, as is presented in the following sections, the touring ecosystem proposed, provides the ability to generate a digital gift such as a collage-post card of photos and selfies, uniquely personalized.

To support our approach, we have built and run a fully working prototype in the touristic center of Athens, Greece, with real users and designers for several weeks during summer time. The feedback received is extremely positive and encouraging. 


\section{Tour Process State of Play and Current Environment}

As it seems, tourism is now interconnected with various sectors of information technology, which, until recently, came to meet the needs of people working in tourism. As mentioned, IT provided various solutions such as corporate accounting systems, booking systems, room and route management, etc. However, the presentation of the touristic product, did not follow the same development. The maps were given in printed form, the instructions for a tour in the form of a booklet, and whichever where the travel agent's recommendations and notes were given to the tourist in various extemporaneous ways.

The tour process passed almost completely into the hands of specialized staff (e.g., guides) who possessed the necessary information —and not always knowledge-while the tour program was designed by specialized or non-specialized staff, based on factors such as the shortest route, or travelers pass through points of commercial interest, where the selection criteria were again vague. What determined a tour was the time available, the ease of access, parking spaces, etc. The best case scenario was that the tour was evaluated by how happy the group of travelers was at the end of the tour and not by individual feedback from the travelers.

The indication of where the solution lies was brought at first by the printed and then electronic tourist guides. At some point tourism flourished and people started leaning on their own plan for booking tickets, hotels to go to and what to see. By purchasing a thick printed volume or visiting a website, the visitor could obtain information about the points of interest and sights of a city, archaeological sites, theaters and restaurants, but again, this content, either in print or online form, was characterized by three problems as described below.

First, the visitor who bothered to read the tourist guide made the choice of where to go, but the choice was one of the suggested points presented inside the guide. The collection of the presented locations was the result of filtering and choice of the guide's authors. That means that many points of interest might be left out from the guide, so the visitor did not even learn of their existence.

Second, the amount of information in a book or website was too large for the visitor to discover, almost being impossible to figure out all the locations that might interest her.

Finally, the whole planning process had to be completed before the trip, with different means and various sources, while during the tour, the visitor had to have with her again, in printed or electronic form, a map and a guide to guide her in this tour.

\section{Related Work}

\subsection{Touristic Memorable Experience}

Tourism is a phenomenon that offers visitors memorable experiences [5]. These memories and customer experiences lead to successful tourism products [6]. However, from a practical point of view, the design and implementation of memorable experiences for tourists is a problematic situation due to the personal point of view and the character of each consumer [7]. It has been shown that memory can be identified as an important dimension to the tourist experience [8]. The concept of originality is of paramount importance in understanding the tourist experience [9]. Originality can also be a stimulus for a tourism activity, when designing it [10].

All the above lead us to the fact that the goal for a touristic product is the memorable tourist experience with original elements. The experience from its design to its implementation goes through various stages such as orientation, connection, visit, evaluation, storage, recall and enrichment [11]. This model has been proposed since 2001 to create a model for a general theory of tourism experience. Note that these comments were made in 2001, 3 years before the creation of the most popular social networking medium (Facebook Inc., founded February 2004). After all, the way information was communicated about our travels before the existence of social media, some can recall (the older ones at least), that printed photographs were shown after a trip. Friends, acquaintances, relatives or even 
participants in the trip gathered in a house to see, remember and show to those who did not participate, photos, videos and other souvenirs [4].

This sharing of experience is deeper than just a demonstration of experience. The person who lived the experience may like to share their experience, but there are certainly viewers who will want to see this experience. They may be motivated by it and in turn become willing to become involved in the experience themselves.

The study of the basic parts of a memorable experience shows that there is a separation of three stages: before, during and after the trip [12]. The findings of this study show that most memories come from the third stage of this process, when the journey is over, and we recall our experiences and compare them with other experiences to see how they differ.

This is another point where the value of the souvenir [4], and especially the original souvenir, acquires special value. If, at the end of the trip, we recall our experience and evaluate it, surely the more original, special and descriptive the souvenir is, the more special our memory will be. Definitions of originality in psychology can be synonymous with something we do not expect, that can be complex, atypical, uncertain and generally something we have not experienced before [13]. Originality in tourism has been defined as the extent to which the experience differs from the visitor's expectations [14]. So, in this age of easy communication and sharing of experiences, the age of the wisdom of the masses with social media reviews, it seems that while the souvenir has changed from the past and will always change form, at the same time, it will be legitimate for every traveler.

A tourist who uses a certain application to create his souvenirs might take some photographs from his trip and apply the same filters or create the same collage with other photographs from other trips. Since the souvenirs are identical, only the depicted image is changed, and the rest of the souvenir is the same as many other users that might have used the same service or application. The same applies between two tourists visiting two entirely different vistas and using the same filters and collages. However, this repetition of the outcome reduces the originality $[13,14]$. What if there was a graphic designer and a photographer suggesting ways to take pictures and make a collage out of them, in every different case? The work presented here shows how this is possible and how an original and memorable experience can be achieved if every visit has special, unique characteristics that can be employed in the souvenir.

Today, perhaps more than ever, the memorable experience dictates the services of the professional photographer and professional graphic designer, along with the help of technology, so the creation of original and memorable souvenirs is feasible.

\section{2. e-Guides}

There are literally dozens of applications for sightseeing and route tracking. The three major categories are:

1. Applications where users download an application/tour guide then select the places to visit and these applications find them perhaps the best route on the map, or even information about points of interest;

2. Applications that are made specifically for a city or a service, and the user can take advantage of their capabilities if they specifically visit that city or location;

3. Applications that offer the creation of a browsing experience. That is, platforms that offer templates and anyone can create content for their visitors. Recipients of this service are not the direct users but hotels, municipalities, exhibition centers, etc. These bodies will make the guide through the platform and will give it to their respective end user.

Nevertheless, these apps fail to produce a result that will represent the memorable times one had during his visit, vacation and routes traveled in a tourist destination. Sure they show the way to follow and provide some info, but they are serving mostly as a tool to guide the tourist around but with no memorable value afterwards other than sharing instance-photos. 


\subsection{Personalized Printed Posters and Media Package Souvenir Appification}

Sakkopoulos et al. [4], in 2005, presented how appification had been introduced to describe the rapidly widening shift from web browsing to the usage of smartphone apps for Internet-based information access and e-services consumption. This work showed how user involvement can be increased when, instead of buying a physical souvenir from a museum, a personalized e-souvenir [4] can be formed and acquired by the user combining ready-made photos and videos into a single multimedia package. This is the first time that the user intervened into forming a representation of their own memories into a digital token. However, no further personalisation has been included. It is also shown how QoS assurance techniques enable efficient media delivery through smartphones to assist making the old-fashioned shopping souvenirs go online and become virtual.

Kunieda et al. [15] presented a way of how collaboration of various sectors, institutes and organizations could produce a regional problem-solving information system through an agile development process model. They addressed problems such as local advertisements (with KadaPos), travel diaries (with KaDiary) and tourist guidebooks (with KadaPam). All three solutions offered a personalized information brochure printed out for each problem. So, the person interested in the solution could reach a predefined physical printing system and receive the aforementioned brochure. In this case, personalisation has been used to produce a final printed product-a map — and no digital transformation is employed at the end-users' hands but only for the backend.

\section{Solution Architecture}

The presented solution is divided into several sections (or layers) which cooperate and communicate with each other while being comprised of more than one subset. Such an implementation is found as a multi-layered or as a multi-tiered solution. Several different technologies were implicated for the final result, each with its own peculiarities and limitations. In this chapter, we will deal with this separation, and how this separation is involved with the different technologies and design patterns per case. The purpose of this approach is ultimately the separation of the concerns of each part of the proposed solution, with the ultimate design purpose being the detachment of the various consisting parts, so if the case arises, there will be development only on specific parts of the application.

\subsection{User Experience-Top Tier}

The top tier (Presentation layer/user interface), as presented in Figure 3, will be visible to the user. Through this level, the user browses, defines his options and receives the results of his personal preferences and choices. To support all clients, a web application with the principles of PWA (Progressive Web Applications) is employed, providing flexibility and giving the look and feel of a locally installed (native) application.

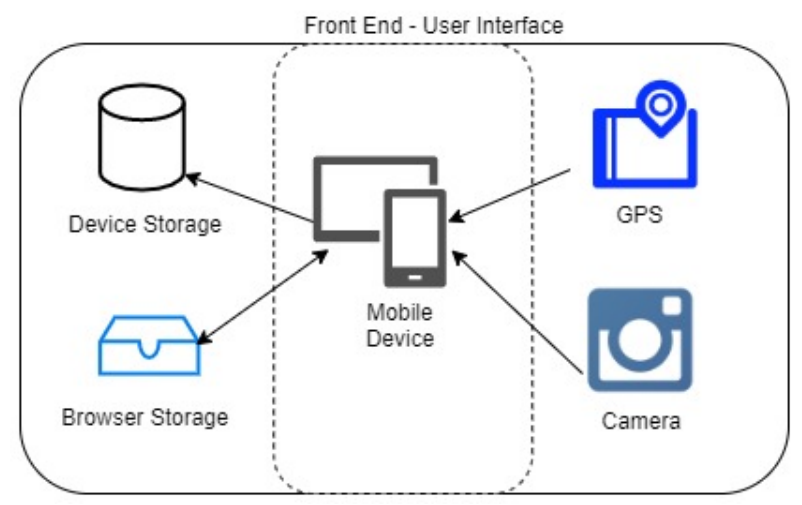

Figure 3. User Interface. Abstract representation of how the mobile device communicates with various local resources. 
The user experience and interface level, however, is not limited to presenting only data and information in a way that looks like a native application. It is responsible for communicating and receiving data from the device's positioning subsystem (GPS-global positioning system) as well as from the device camera. It also utilizes the ability to store data both on the device and in the browser's local secure data storage. This kind of communication is performed at the front-end utilizing web technologies as defined in MDNWebDocs (Mozilla Developer Network), especially in the modules for geolocation and webRTC.

\subsection{Web API-Middle Tier}

Any communication goes through the intermediate level of services, the Web Application Programming Interface (WebAPI). In multi-tier solutions such as the one that is presented here, this layer holds the intermediate position and is referred to as the middle layer or middle tier, as depicted in Figure 4.

These calls, which the intermediate level can respond to, are organized into controllers, and there is a logical structure to the paths that must be followed to make the call correctly. This schema allows for individual modification if only one of the controllers is needed, reuse, multiple people working on them at the same time, etc. For example, all service calls follow the REST (Representational State Transfer) standard, and all calls are below the interface/api path of the interface.

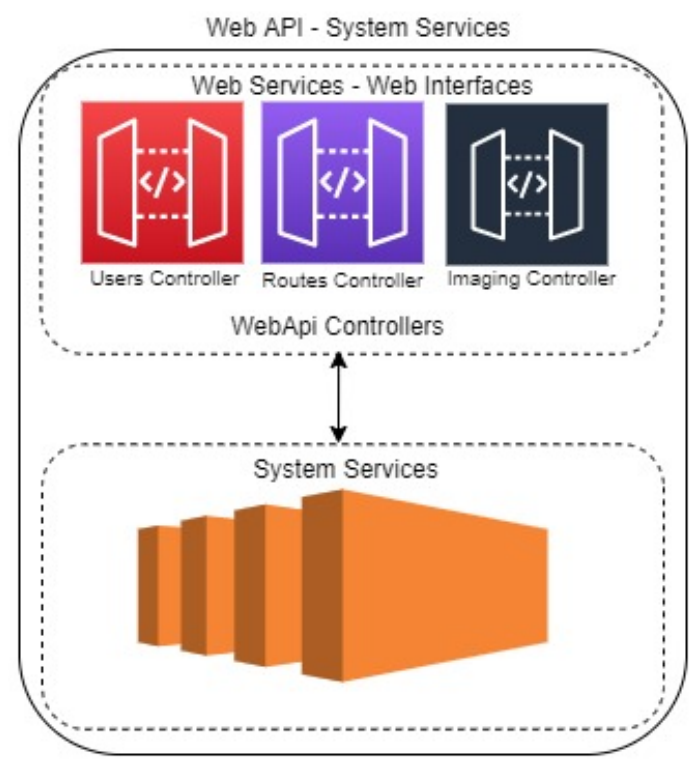

Figure 4. Middle tier. WebApi and System Services.

While the front-end is almost autonomous, the intermediate level is more abstract as a concept and includes both the online service interface of the application services and the internal services of the application which are not "visible" to any external user. So, the intermediate level includes the interfaces to communicate with external applications such as the front-end with our application but also the internal services that are responsible for them in the functions that really make up our application. These internal services will define and coordinate calls to data services but will also carry out the business logic.

\subsection{Repositories-Bottom Tier}

Following the top-down analysis approach, there is the third level, which is responsible for the data, both for extraction and storage, as well as their physical retention in a database Figure 5. In order to detach the functions of database communication from the database itself, there are the repositories that take up this role. 


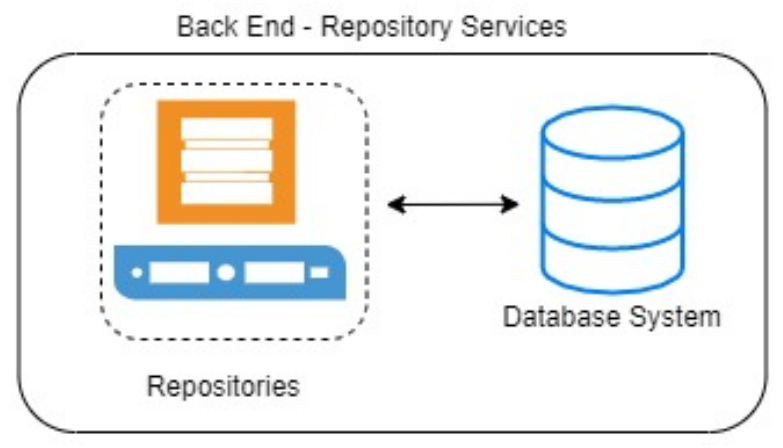

Figure 5. Middle tier. WebApi and System Services.

This allows scaling when needed, or even changing the underlying database system, without affecting the rest of the application architecture. The repositories are responsible for database communication and when data are needed from the database, the request should be performed from the respective repository.

\section{Presentation of User Flows}

The user, after being authenticated, selects a route. The route is followed on a dynamically updated map, and each time the tourist reaches a point of interest, the application informs the user about his proximity, and prompts the user to take a photo.

The key difference from any previous solution is that we provide to the user the option at each point of interest or at the end of the route, to create a personalized e-souvenir forming a personalized memento-a digital souvenir. One may select which guided selfies and images will be used to be included the final souvenir. The digital souvenir is created on the fly dynamically in few milliseconds. The personal e-souvenir is sent back to the user's device, where it can be stored locally, shared to various social media or sent to other people through direct messaging applications (DM apps). It has been considered to be easier than buying postcards in every other stop or route visit by our interviewers.

In Figure $6 \mathrm{a}-\mathrm{d}$, the features of the application are presented.

\subsection{Route Listing and Selection}

After authentication, a list of available routes are presented, displaying their name, the length of each, and the total number of points of interest that make them up.

Special offline support has been designed for this part. All assets are downloaded on the fly dynamically and asynchronously. This means that everything related to the routes, points and auxiliary photos are fetched during this step, and from now on, the whole application will run smoothly without limiting the user experience with connection delays.

\subsection{Location Awareness and Route Overview}

The user may select to be guided or to preview a route using the app. One can simulate the visit or check his distance from each point of the application while on route.

According to Seppo K. Aho, the travel experience begins with the traveller's acquaintance with the journey (orientation) to create some interest and what he is going to see during it and continues with his connection (attachment) with the trip in order to strengthen the desire to finally make the trip happen. This point of the application aims at exactly this result: not only to guide the user but also to give him a taste of the experience he is going to gain. 


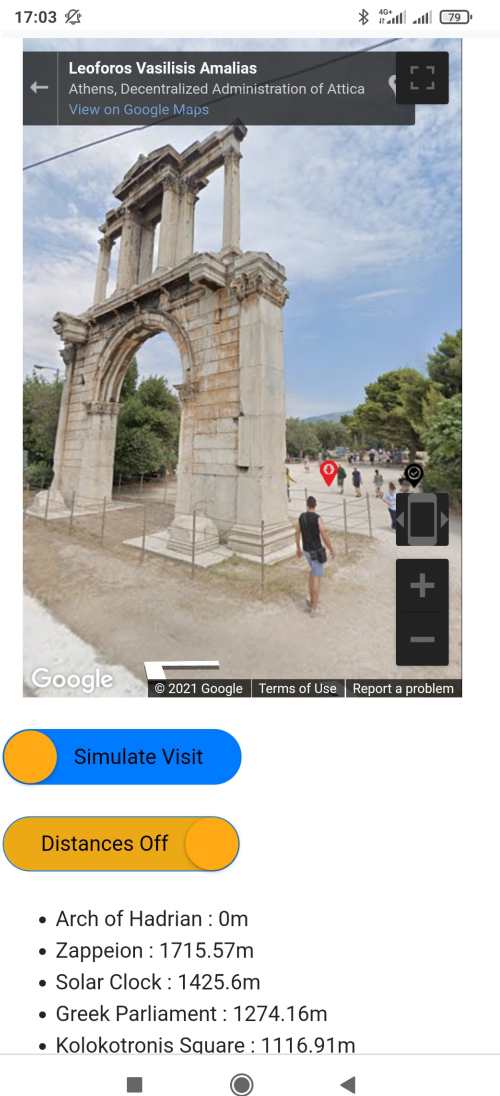

(a)

Stored Images Found : 4

Choose from the list below, the pictures you wish to use for your souvenir.

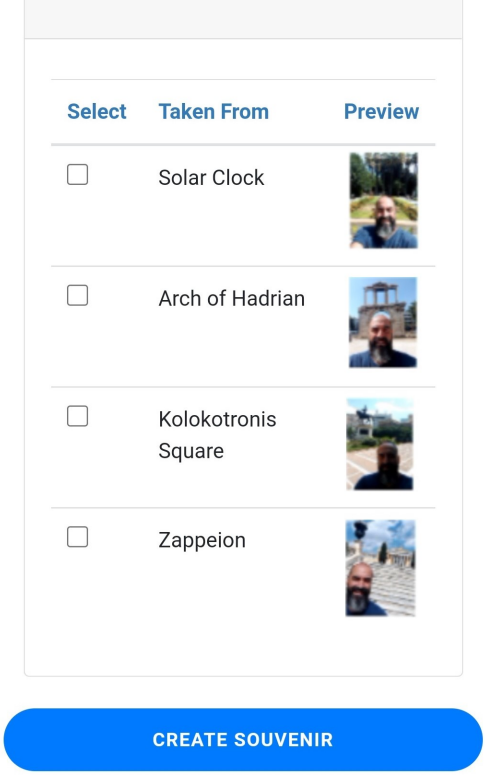

(c)
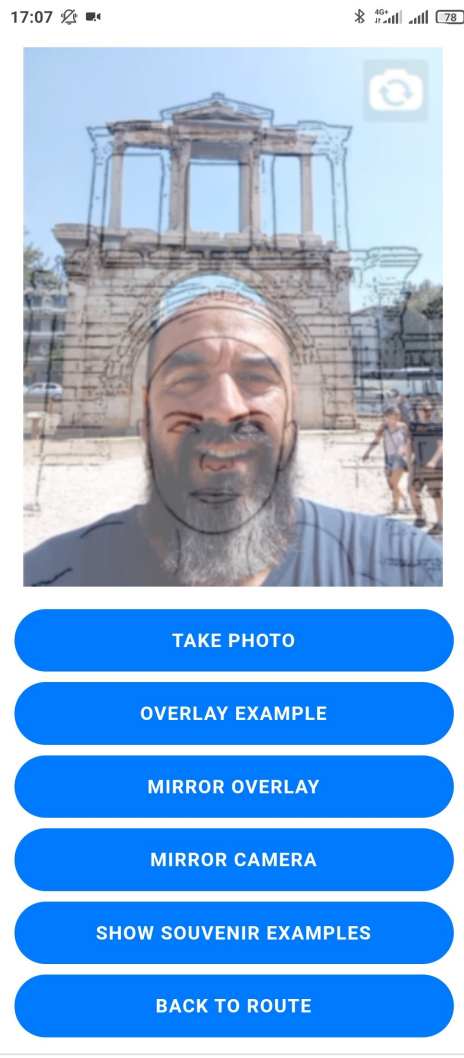

- 0

(b)

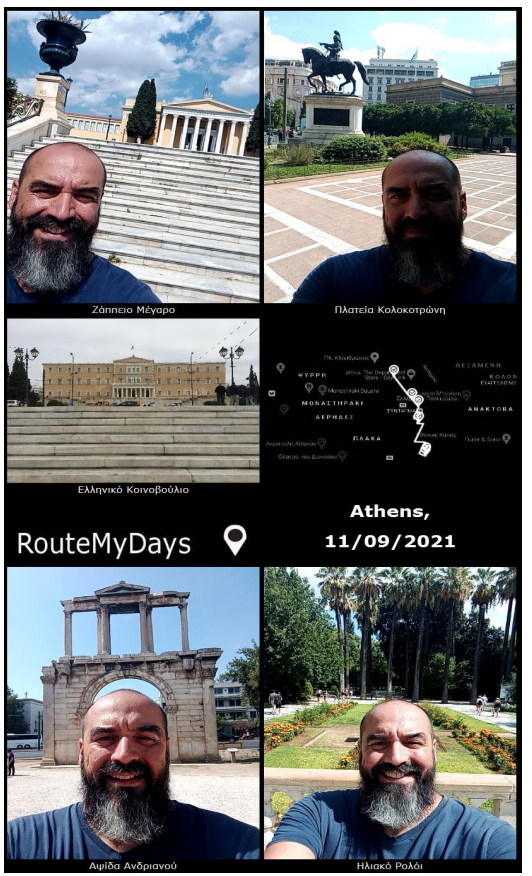

(d)

Figure 6. Various features of the application: (a) Displaying distances, position awareness and Google street view functionality; (b) Taking a selfie at a point, while assisted with a watermark; (c) The list of photographs that can be selected for the final e-souvenir; (d) the final e-souvenir. 
In the simulation mode, the user can prepare himself for the visit or experience a virtual tour using street view options. The application takes advantage of Google's ${ }^{\mathrm{TM}}$ street view service and allows the user to see the environment in virtual mode, without leaving the application. This is a feature that can also be helpful to explore the surroundings before starting his visit.

When the user activates the street view service, his virtual location is displayed where he dropped the pin. In a portable device with rotation and orientation capabilities, it is possible for the user, even while in the comfort of his hotel, to explore the location he is interested in and the environment around it. This way, it will be easier to identify the points of interest when approaching them [16]. This is also a key element of the user experience.

On route, when the visitor approaches a predetermined distance from the point of interest (for example, $25 \mathrm{~m}$ ), this proximity is perceived by the system, and it suggests the procedures that are available when we are close to a point (Figure 6b). For example, the user can take a photo, go to the souvenir personalisation screen or view souvenirs available for him at this point. The designers, photographers and guide professionals may develop a number of different souvenir formats to make them available to the user for personalisation with selfies!

\subsection{Photographic Example and Text Guide about the Shot}

As soon as the visitor clicks on the "take a photo" button, and before the image is captured by the camera, the system, recognizing the point from its proximity, displays the instruction text and shows an example capture for that point. This is performed both for the user to read the instructions on how to position himself and to see an example of what the "ideal" download would be, according to the route creators.

\subsection{Taking the Shot and Watermark Examples}

Activating the camera brings the user to the camera's live feed preview. Initially, only the camera is visible, but if the user wishes, he can see a sketch of the shooting example in the form of a watermark (Figure $6 \mathrm{c}$ ). This shows the basic elements of the location for the user to be placed, as well as the proposed idea to place his face. From this point, the actual photo can be taken. In addition, if the user wishes so, the three forms of souvenir models can be presented.

\subsection{Various Forms of the Final Souvenir}

From two different sections of the application (route tracking-Taking a photo), it is possible for the user to switch to the display of final souvenir forms. This way, the user can know what is expected to be created and what the final souvenir will look like. This function plays the role of keeping the user engaged, and the browser is not in a state where the system suggests and takes pictures without knowing how to use them. It is an important part both before and during the route in order to maintain the user's engagement with the route.

These three forms are included in the route structure, and as it is shown, the date will be dynamically filled to be another personalized element of the user on the final souvenir. The creation of such a form presupposes the collaboration with professional photographers and graphic designers for a better aesthetic result. The illustration of the formats below is one of the two paths that have been set up for our application. These three forms are:

- $\quad$ Only the landscape of each location;

- The landscape of the location, along with the model shot;

- The landscape of the location, along with the model shot in a sketch form.

For another route, there might be a completely different layout of the souvenir elements. In both the graphic design and the spatial approach, two different arrangements of souvenirs were made to demonstrate the possibility of creating different aesthetic results, with minimal restrictions. Two totally different layouts (templates) are shown in Figures 7 and 8 . 


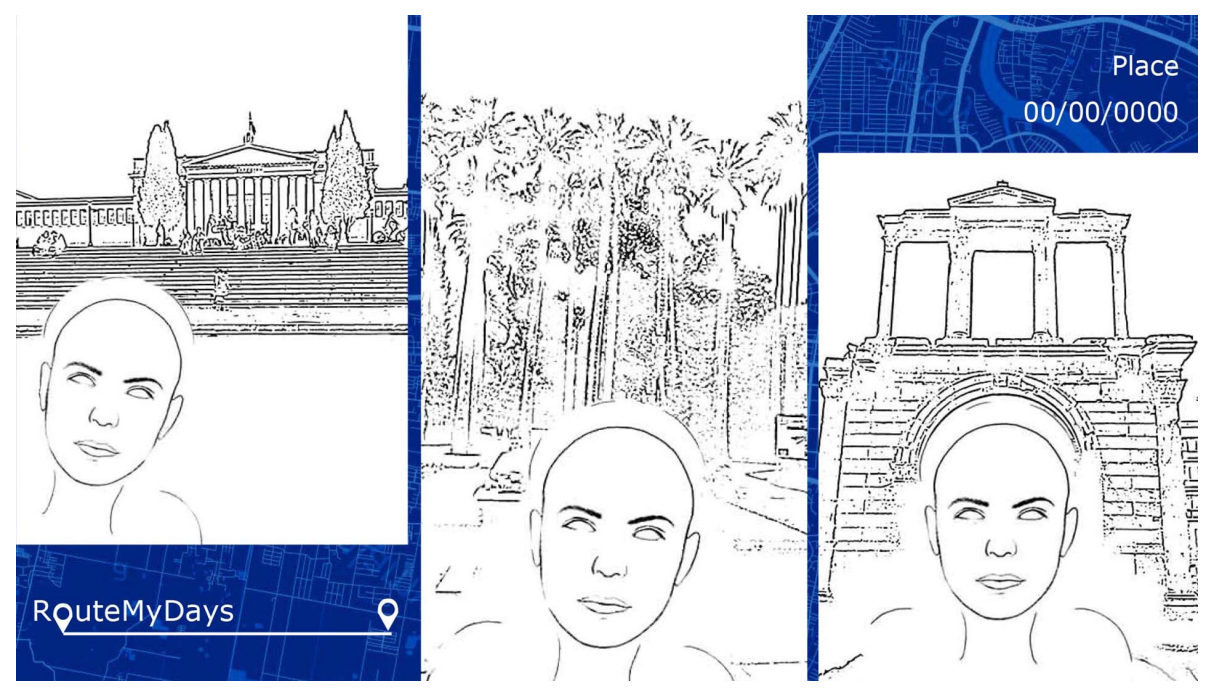

Figure 7. Sketched layout of a souvenir (horizontal).
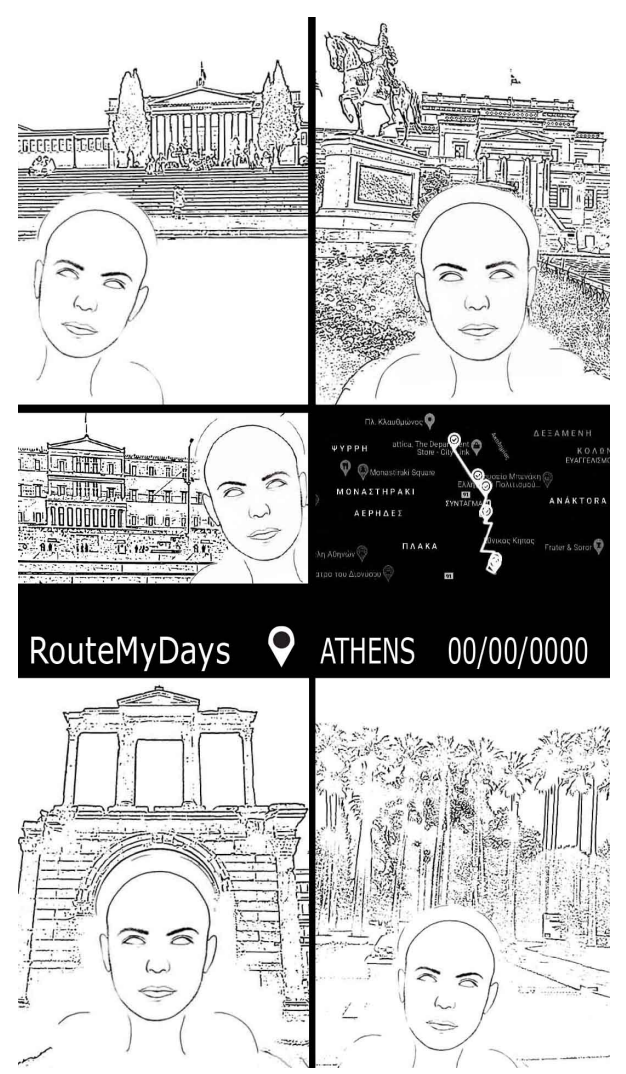

Figure 8. Sketched layout of a souvenir (vertical).

Of course, only the souvenir with location landscapes is available to the user, unless he selects a photo taken previously to replace the default landscape. The other forms are listed to show the stages that the application goes through.

\subsection{Creating the Personalized Enriched Souvenir}

As shown, depending on the route chosen, there is a souvenir that will be produced at the end. This is the second point where communication with the server is needed, and there may be a connection delay. The advantage here is that the creation of a final souvenir can be performed off-road, at any time, as soon as the user returns to an environment where there is a faster network available. 
The user needs only to open the application again, simulate the visit to a point and from there choose to create a souvenir. The captured photos remain in the local storage of the browser until the relevant files are deleted by clearing the history of each browser. From there, the user can select which photos will be includes in the e-souvenir (Figure 6d).

\subsection{Complete Overview}

The main business flow of the solution from the end-user perspective is shown in Figure 9 .

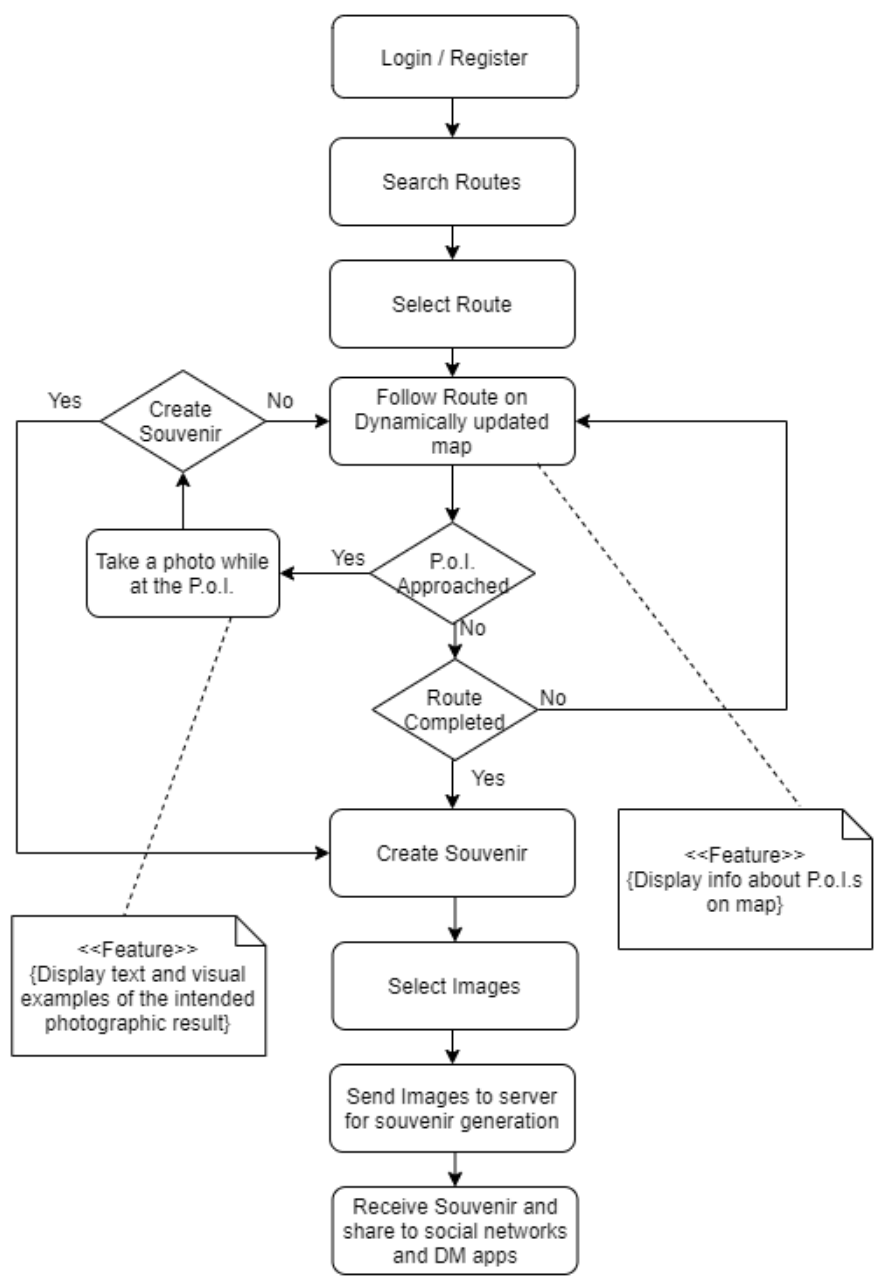

Figure 9. Basic flow from the user perspective.

\section{Experimental and Real User Evaluation}

The solution has been evaluated with real users using a fully working prototype implementation functioning on Android, iOS, Windows and Linux systems. The evaluation included research on both its usability and the value of the solution it offers. For this purpose, a questionnaire was prepared which includes 14 questions, of which 10 are related to the system Usability Scale (SUS-System Usability Scale) [17] and 4 are related to the user's disposition or intention towards the type of application in general.

In the survey conducted in July 2021, 17 people participated in a real-life evaluation of the proposed approach walking around as tourists, and after being explained the purpose of the work, the application and the questionnaire, they were given a link to use the application, without being given any instructions on how it is "expected" to use the application. Users had the opportunity to actually visit the points of the route and create a souvenir on the spot or alternatively by using the function of simulating a visit and again creating a souvenir, this time only by simulating their visit. 
The first 10 questions related to usability were adapted to our case according to the methodology and the questions described in relevant work [17]. Users had to answer each of these questions on a five-point scale from 0 (Strongly disagree) to 5 (Strongly agree). The scores that the testers provided for the 10 questions of the SUS are shown in Table 2.

Then, the scoring methodology was followed, and the usability index was extracted. More specifically, the average for each answer came out (AVG), and for each question with odd numbering, 1 (AVG-1) was subtracted from the score, while for even questions, this average was subtracted by 5 (5-AVG). In an SUS questionnaire, odd numbered questions have a positive meaning and translation, while even numbered questions express a negative one. These values were then summed and multiplied by 2.5 . What results is not a percentage, but it is a scale with a maximum score of 100 .

Table 2. Scores of System Usability Scale related questions.

\begin{tabular}{ccccccccccc}
\hline & Q1 & Q2 & Q3 & Q4 & Q5 & Q6 & Q7 & Q8 & Q9 & Q10 \\
\hline AVG & 4.59 & 1.59 & 4.71 & 1.47 & 4.65 & 1.24 & 4.47 & 1.24 & 4.35 & 1.29 \\
\hline AVG-1 & 3.59 & & 3.71 & & 3.65 & & 3.47 & & 3.35 & \\
5-AVG & & 3.41 & & 3.53 & & 3.76 & & 3.76 & & 3.71 \\
\hline
\end{tabular}

The Usability Index in our case scores 89.85 points, which indicates that the application can be considered very easy to use.

Further questionnaires are also employed to obtain the user's intentions towards this kind of application. Questions included topics for survey such as:

1. I use mobile application in everyday life;

2. I have prior experience using geo-content applications (GIS-e.g., guidance applications, finding the best route, GPS in the car, suggesting places of interest, etc.);

3. I like the idea of a personalized e-souvenir when in tour or in a trip;

4. I like the idea of an app suggesting the place and the way taking a photograph for an e-souvenir.

The scores for these questions are shown in the following bar charts (Figures 10-13).

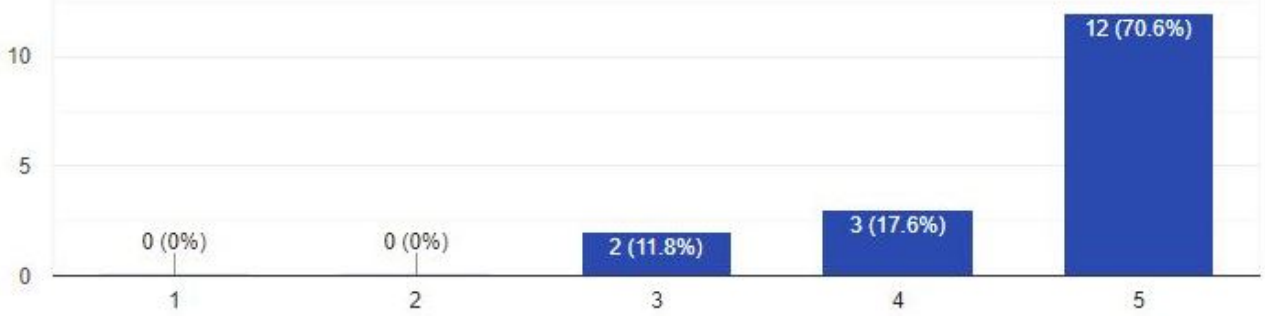

Figure 10. I use mobile applications in everyday life.

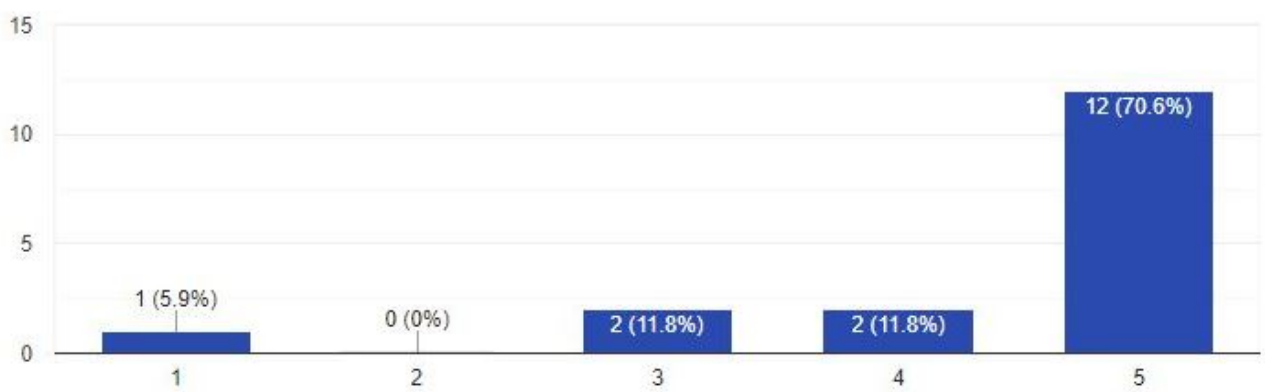

Figure 11. I have prior experience using geo-content applications. 


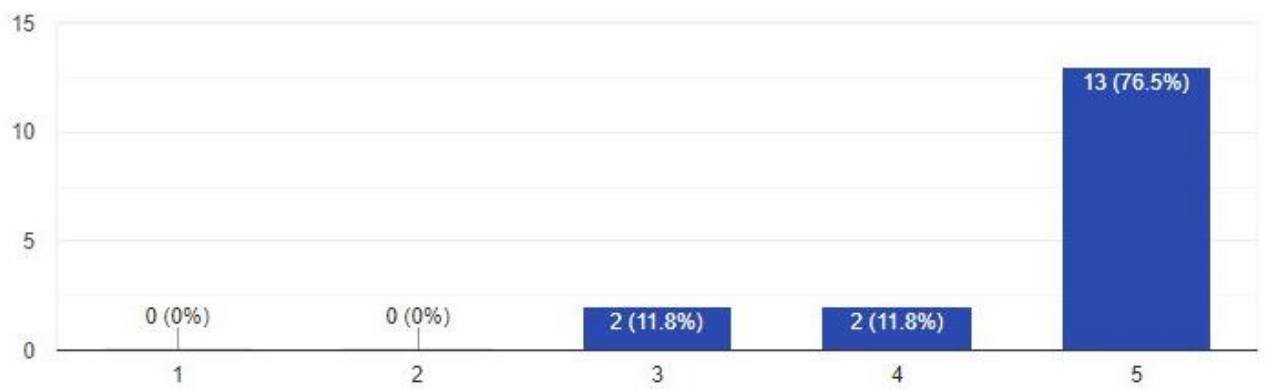

Figure 12. I like the idea of a personalized e-souvenir when in tour or in a trip.

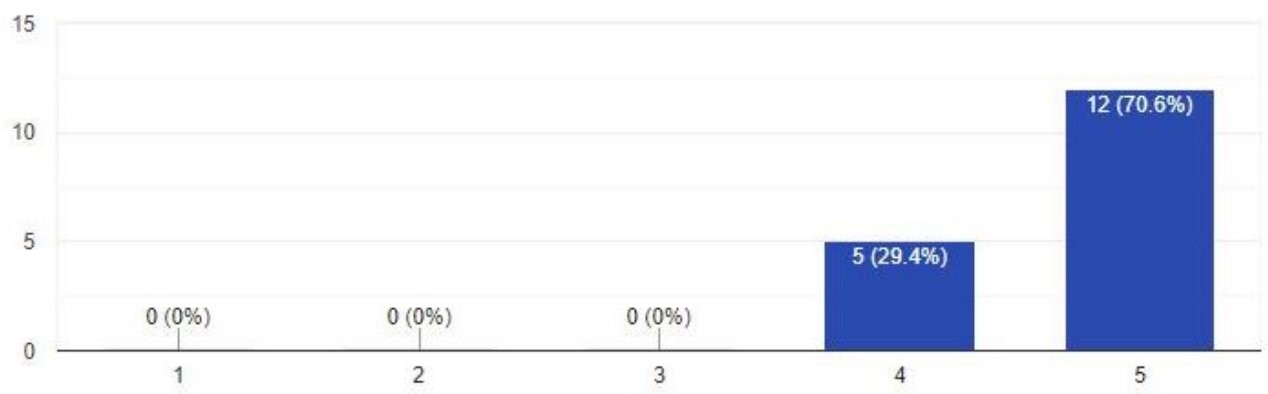

Figure 13. I like the idea of an app suggesting the place and the way taking a photograph for an e-souvenir.

These charts confirm that the idea of a personalized e-souvenir through a guided process by a mobile application is something that users will appreciate and that the acceptance of such a system is most likely to be broad.

\section{Conclusions}

In this paper, an attempt was made to find a way to create a personalized souvenir for the best touristic experience of the user. A wide range of technologies was used, both for mobile devices and for server-side development. The approach to the problem had to be and was multifaceted. We studied what the majority of a sample of similar applications offered and in what categories these applications could be categorized. Then, we delved into what has been observed and studied theoretically to conclude that the user experience has a prominent place in tourism. There are many good navigation systems, optimal route finding systems and points of interest pointing/suggestion systems, but the value of the souvenir always remains prominent in the mind of the traveler.

So, a multifaceted application was analysed and designed, which, in order to achieve its purpose, would have to "marry" many different technologies, each with its own limitations. Both the user experience while using the application and its performance were examined. Connection security, loading speed, frequency of communication with the server, immediacy in position monitoring and communication of the application with the resources of the device were examined and evaluated during the analysis stage.

The final outcome is a complete ecosystem for creating memorable users experiences, characterized by novelty and ease of use. Such an application is created for the first time, combining attributes of previously created solutions as long as adding new features to fill what current solutions might lack. The high evaluation of both the idea and the implementation shows that there is a potential for high immediate business impact.

Future research and implementation could contain means of ownership of this personalized e-souvenir. As the photograph and the corresponding negative film or a printed cart-postal is considered to have a legal owner and so should be the case for the e-souvenir. Digital ownership could be achieved through block-chain technology [18]. Future implementations could provide the creation of NFTs either through proof of work (PoW) 
protocols such as EIC-721 [11] or by using proof of stake (PoS) protocols [19] such as FLOW, Tezos, Solana, etc.

This way, the application could request to connect with an NFT-capable crypto wallet and the personalized e-souvenir would obtain a smart contract and be converted to an NFT as soon as it is created. Then, the user could rightfully be self-proclaimed as the owner of the souvenir or even allow the creation of certain "approved" number of collectible copies.

Of course, for all of this to happen, a lot of prerequisites have to be met, and a lot of the current state of NFT business must be altered, since there are still some major questions to be answered. Such issues are environmental concerns (especially because of how PoW works) or other various fees that are required in some cases.

Author Contributions: Conceptualization, E.S.; methodology, E.S.; software, P.M.; validation, P.M., Z-M.I., E.V. and E.S.; supervision, E.S.; funding acquisition, E.S. and G.P. All authors have read and agreed to the published version of the manuscript.

Funding: This research has been co-financed by the European Union and Greek national funds through the Operational Program Competitiveness, Entrepreneurship and Innovation, under the call RESEARCH-CREATE-INNOVATE (project HappyCruise, project code: T1EDK-03715).

Institutional Review Board Statement: Not applicable.

Informed Consent Statement: Not Applicable.

Acknowledgments: We would like to gratefully thank Asimina Mantas for the design of the initial selfie previews as well as all the early adopters and reviewers of the proposed solution for their helpful and encouraging feedback. This research has been co-financed by the European Union and Greek national funds through the Operational Program Competitiveness, Entrepreneurship and Innovation, under the call RESEARCH-CREATE-INNOVATE (project HappyCruise, project code: T1EDK-03715).

Conflicts of Interest: The authors declare no conflict of interest.

\section{References}

1. Institute of Greek Touristic Companies. Press Release 29 May 2019, Tourism Contribution in Greek Economy of 2018. Available online: Https://insete.gr/wp-content/uploads/2020/02-/190529 \char'_PR-INSETE \char'_Simvoli \char ${ }^{\prime} \_$Tourismou \char' 2018.pdf (accessed on 21 October 2021).

2. National Bank of Greece. Press release 29 June 2020, National Bank of Greece's Report for Monetary Policy of Years 2019 2020. Available online: Https:/ / www.bankofgreece.gr/enimerosi/-grafeio-typoy/anazhthsh-enhmerwsewn/enhmerwseis? announcement=cf55db30-b069-489d-9933-46af32f83a9a (accessed on 21 October 2021).

3. da Silva Lopes, H.; Remoaldo, P.C.; Ribeiro, V.; Martín-Vide, J. Effects of the COVID-19 Pandemic on Tourist Risk Perceptions-The Case Study of Porto. Sustainability 2021, 13, 6399. [CrossRef]

4. Viennas, E.; Ioannou, Z.-M.; Pavlidis, G.; Tzimas, G.; Sakkopoulos, E. HappyCruise: An architecture for Personalized Secure Boarding on Cruises. In Proceedings of the 2020 11th International Conference on Information, Intelligence, Systems and Applications IISA, Piraeus, Greece, 15-17 July 2020; pp. 1-8.

5. Weiler, B.; Torl, M.; Moyle, B.D.; Hadinejad, A. Psychology in Tourism Doctoral Research. Tour. Recreat. Res. 2018, 43, $277-288$.

6. Williams, A. Tourism and hospitality marketing: Fantasy, feeling and fun. Int. J. Contemp. Hosp. Manag. 2006, 18, 482-495. [CrossRef]

7. Knobloch, U.; Robertson, K.; Aitken, R. Experience, emotion, and eudaimonia: A consideration of tourist experiences and well-being. J. Travel Res. 2017, 56, 651-662. [CrossRef]

8. Oh, H.; Fiore, A.M.; Jeoung, M. Measuring experience economy concepts: Tourism applications. J. Travel Res. 2007, 46, 119-132. [CrossRef]

9. Mitas, O.; Bastiaansen, M. Novelty: A mechanism of tourists' enjoyment. Ann. Tour. Res. 2018, 72, 98-108. [CrossRef]

10. Bello, D.C.; Etzel, M.J. The role of novelty in the pleasure travel experience. J. Travel Res. 1985, 24, 20-26. [CrossRef]

11. EIP-721: Non-Fungible Token Standard. Available online: https:/ / eips.ethereum.org/EIPS/ eip-721 (accessed on 20 October 2021).

12. Park, S.; Santos, C.A. Exploring the Tourist Experience. J. Travel Res. 2017, 56, 16-27. [CrossRef]

13. Förster, J.; Marguc, J.; Gillebaart, M. Novelty categorization theory. Soc. Personal. Psychol. Compass 2010, 4, 736-755. [CrossRef]

14. Ma, J. Emotions Derived from Theme Park Experiences: The Antecedents and Consequences of Customer Delight. Ph.D. Thesis, University of Queensland, Brisbane, QLD, Australia, 2013. 
15. Izumi, R.; Kunieda, T.; Kometani, Y.; Gotoda, N.; Yaegashi, R. A Sightseeing Guidebook Automatic Generation Printing System According to the Attribute of Tourist (KadaTabi). In Joint Conference on Knowledge-Based Software Engineering; Springer: Cham, Switzerland, 2019; pp. 207-213.

16. Sakkopoulos, E.; Paschou, M.; Panagis, Y.; Kanellopoulos, D.; Eftaxias, G.; Tsakalidis, A. e-Souvenir appification: QoS web based media delivery for museum apps. Electron. Commer. Res. 2015, 15, 5-24. [CrossRef]

17. Brooke, J. SUS: A quick and dirty usability scale. In Usability Evaluation in Industry; CRC Press: Boca Raton, FL, USA, 1986.

18. Garcia-Teruel, R.M.; Simón-Moreno, H. The digital tokenization of property rights. A comparative perspective. Comput. Law Secur. Rev. 2021, 41, 105543. [CrossRef]

19. Xiao, Y.; Zhang, N.; Lou, W.; Hou, Y.T. A Survey of Distributed Consensus Protocols for Blockchain Networks. IEEE Commun. Surv. Tutor. 2020, 22, 1432-1465. [CrossRef] 